\title{
PLEOMORPHIC ADENOMA OF THE NASAL SEPTUM- A CASE REPORT
}

\author{
Merin Sara Mathew ${ }^{1}$, Haritosh Kamalakar Velankar², Yessukrishna Shetty33, Yogesh G. Dabholkar
}

${ }_{1}^{1}$ Postgraduate Resident, Department of ENT, D. Y. Patil Hospital and Research Centre, Nerul, Navi Mumbai.

${ }^{2}$ Professor, Department of ENT, D. Y. Patil Hospital and Research Centre, Nerul, Navi Mumbai.

${ }^{3}$ Assistant Professor, Department of ENT, D. Y. Patil Hospital and Research Centre, Nerul, Navi Mumbai.

${ }^{4}$ Professor and HOD, Department of ENT, D. Y. Patil Hospital and Research Centre, Nerul, Navi Mumbai.

HOW TO CITE THIS ARTICLE: Mathew MS, Velankar HK, Shetty Y, et al. Pleomorphic adenoma of the nasal septum- A case report. J. Evolution Med. Dent. Sci. 2017;6(87):6081-6083, DOI: 10.14260/jemds/2017/1320

\section{PRESENTATION OF CASE}

A 43-year-old male patient presented with a 1.5-year history of progressive left nasal septal mass (Fig.1) leading to left nasal obstruction for the last 1-1.5 years, two to three episodes of mild epistaxis and gradually enlarging mass involving the left nasal cavity. There was no history of previous trauma, surgeries or visual defect. His general health was satisfactory with a stable weight.

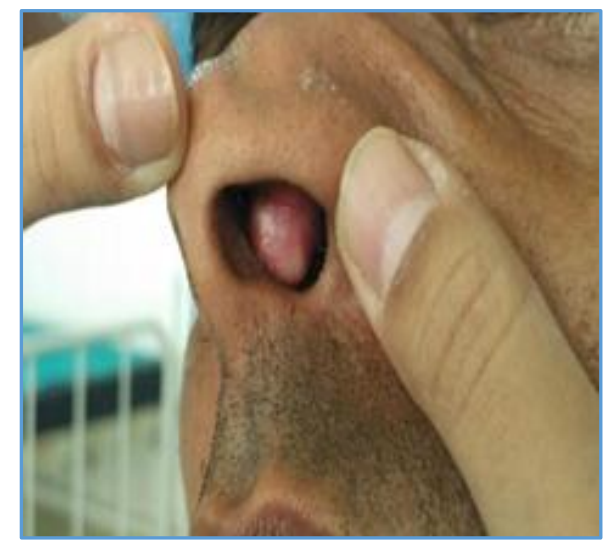

Figure 1. Mass seen in the Left Nostril

\section{DIFFERENTIAL DIAGNOSIS}

Salivary gland tumours account for about $3 \%$ of all neoplasms, the majority being benign and about $70 \%$ are pleomorphic adenomas. A small minority are also located in nasal cavity, neck and oral cavity. In this case report, we are presenting a rare case of pleomorphic adenoma of the nasal septum. Nasal septum is a discrete area of erectile tissue in the submucosa over the anterior nasal septum. In most cases, it can present as a suspicious lesion. Several benign lesions of the septum like leiomyoma, osteochondroma and transitional cell papilloma can be considered. Other malignant tumours such as melanoma, adenoid cystic carcinoma and squamous cell carcinomas may be the differential diagnosis. The majority of these tumours arise from the mucosa of the bony and cartilaginous septum. However, depending on the size and location, the diagnosis may be considered.

'Financial or Other Competing Interest': None.

Submission 09-09-2017, Peer Review 03-10-2017,

Acceptance 09-10-2017, Published 30-10-2017.

Corresponding Author:

Dr. Merin Sara Mathew,

B 601, Neel Paradise,

Sector 9, Nerul,

Navi mumbai- 400706,

Maharashtra, India.

E-mail:drmonu6@gmail.com

DOI: $10.14260 /$ jemds $/ 2017 / 1320$

\section{(c) (i) $(9)$}

\section{CLINICAL DIAGNOSIS}

The lateral wall of nasal cavity was splayed laterally by a mass within the left nasal cavity, while the skin over the swelling appeared normal. Anterior rhinoscopy revealed a friable polypoid mass involving the left nasal cavity. A probe could not be passed around the mass, neither did it bleed on manipulation. The mass appeared to arise from the nasal septum but caused minimal or almost no deviation of the nasal septum to the opposite side. There was no evidence of rhinosinusitis and his postnasal space was also normal. There were no palpable lymph nodes. Radiological examination (CT scan) demonstrated a well-defined cystic mass in the anterior part of the septum of the left nasal cavity with well pneumatised paranasal sinuses (Fig. 2). Furthermore, the smooth surface, preservation of mucosal lining and the localised nature of the mass seen in nasal endoscopy were consistent with the benign lesion.

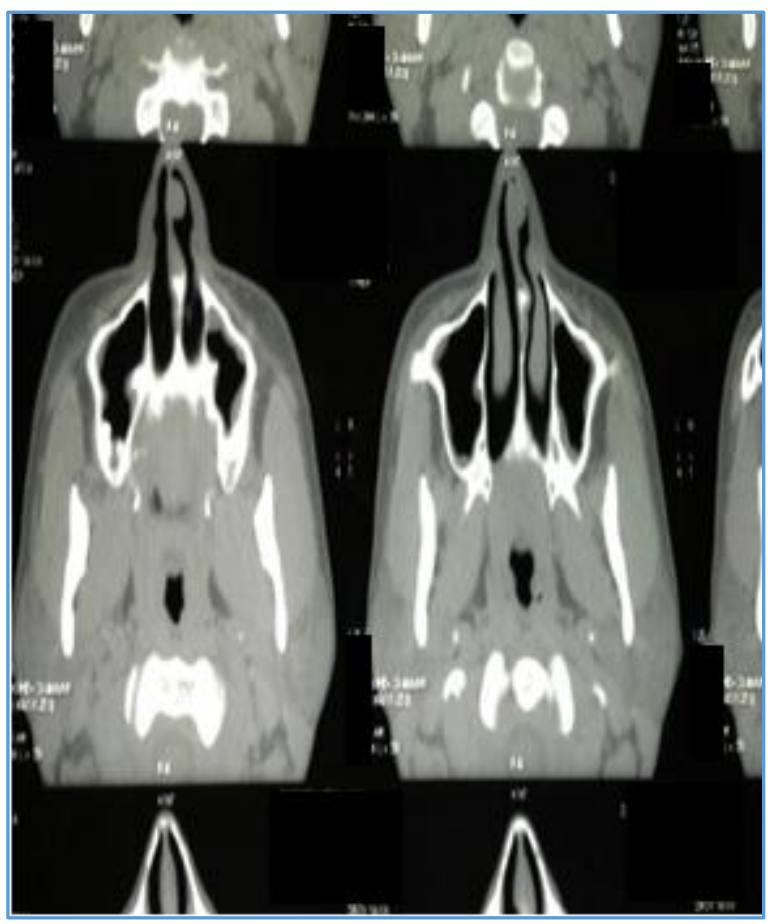

Figure 2. CT PNS Showing Mass in the Anterior Left Nasal Septum

\section{DISCUSSION OF MANAGEMENT}

An intranasal resection of the mass was done and the sample (Fig. 3, 4) was sent for biopsy. The histopathological analysis of the tumour confirmed a benign pleomorphic adenoma with no focus of malignant change. The patient was discharged on day 3 , and the postoperative course was uneventful. After a month, on followup, the patient had no nasal complaints (Fig. 
5) and a repeated nasal endoscopy revealed no recurrence of the disease.

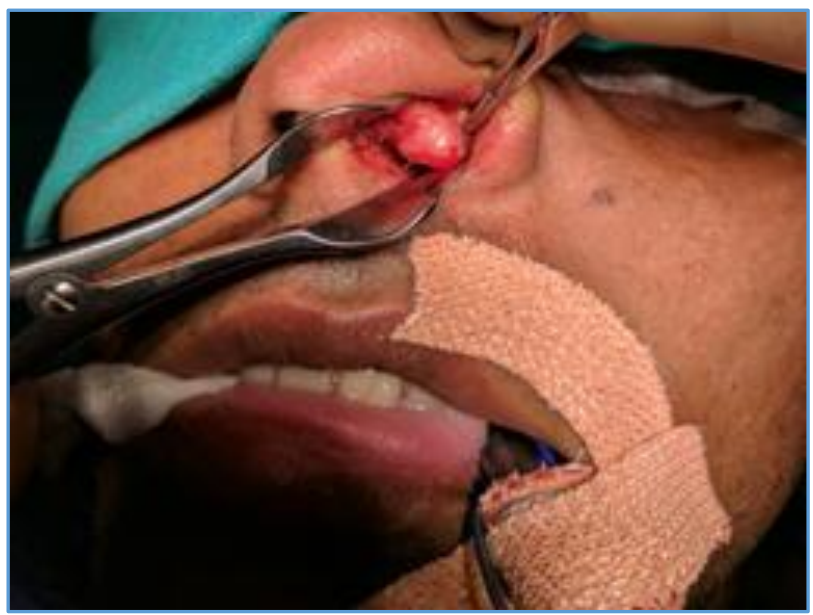

Figure 3. Intranasal Excision of the Mass

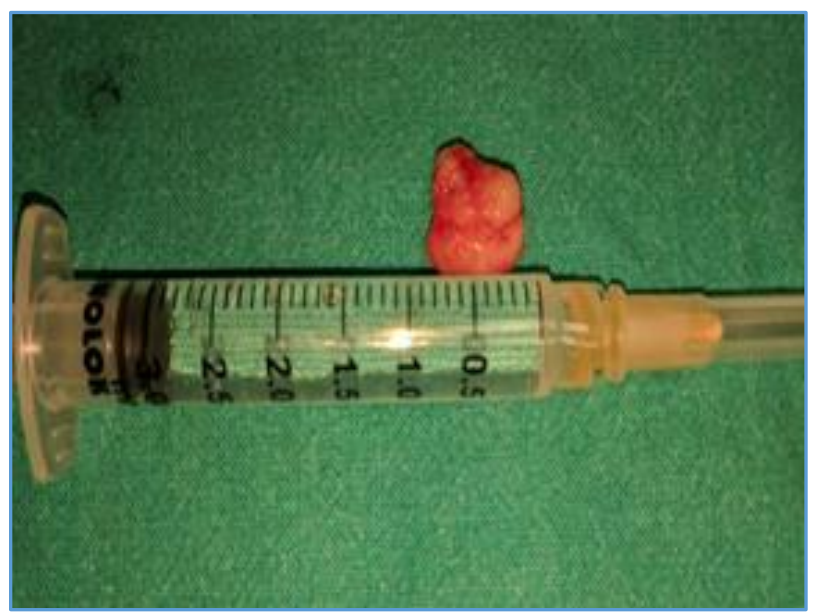

Figure 4. Specimen Removed from the Nose

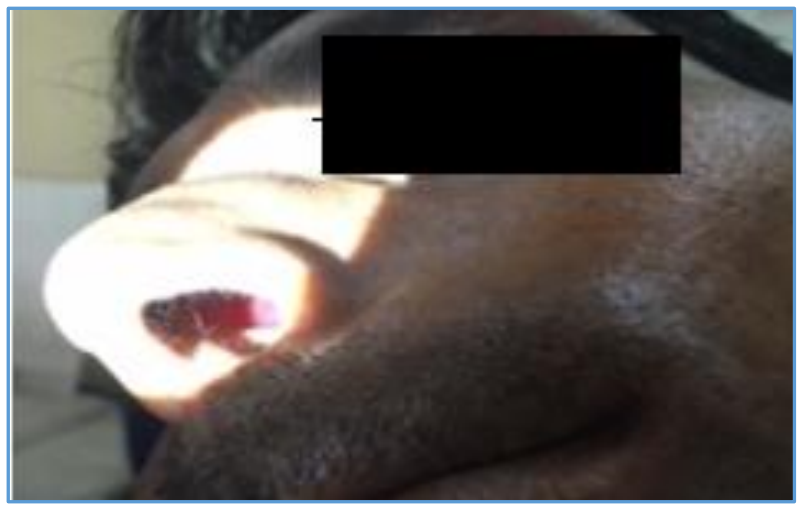

Figure 5. Postoperative Followup

\section{CONCLUSION}

Pleomorphic adenomas are the most common tumour of the salivary gland, but rarely, they can occur in the respiratory tract via minor salivary glands. ${ }^{(1)}$ Cases have been reported in the nasal cavity, paranasal sinuses, nasopharynx, oropharynx, hypopharynx, and larynx. In the upper respiratory tract, the most common site of origin is the nasal cavity, followed by the maxillary sinus and the nasopharynx.(2) The first reported case in the literature of a pleomorphic adenoma of the nasal cavity was in 1929.(3) Although the vast majority of minor mucous and serous glands are located in the lateral nasal wall, pleomorphic adenomas in the nasal cavity mostly originate from the nasal septum.

The tumour presentation is very common in females and usually present between the age of 30 and 60 years. Typical presenting features include unilateral nasal obstruction (71\%) and epistaxis (56\%). Other signs and symptoms include a mass in the nose, nasal swelling, epiphora and mucopurulent rhinorrhoea.(4)

Pleomorphic adenomas are usually characterised by epithelial tissue mixed with tissues of mucoid, myxoid or chondroid appearance but pleomorphic adenoma of the aerodigestive tract may resemble aggressive epithelial tumours because of the high cellularity and lack of a stromal component. Importantly, this feature is not in keeping with that of the major salivary glands which demonstrate relatively reduced myoepithelial cellularity. Occasionally, pleomorphic adenomas are composed almost entirely of epithelial cells with few or no stromata. This can lead to misdiagnosis as a carcinoma.

Wide local resection with histological clear margin is generally followed as the treatment of choice for benign salivary gland tumours. Postoperative radiotherapy has been preached by some authors in circumstances where residual disease was apparent.(5) In the case of intranasal pleomorphic adenoma, several surgical approaches have been used to achieve wide local clearance and these include intranasal, transnasal endoscopic, external rhinoplasty, lateral rhinotomy and midfacial degloving.(6)

The outlook for intranasal mixed tumours is always better than for those in other ectopic sites, because they show early symptoms leading to an early diagnosis. Involvement of the surrounding structures such as bone is rare since the tumours have sufficient space to expand within the nasal cavity.(6)

A neoplasm originating from the nasal septum has a higher risk of malignancy compared to other sites in the nose.(7) Occasionally, pleomorphic adenoma can behave in a malignant fashion, the most common variant being carcinoma ex pleomorphic adenoma which has a potential to metastasise. The predominant metastatic site is bone but spread to lungs, regional lymph nodes and liver has been seen.(8) Ten cases of metastasising pleomorphic adenoma of the parotid gland and three patients with metastatic pleomorphic adenoma of the minor salivary glands have been reported in the literature.(9)

\section{FINAL DIAGNOSIS}

Pleomorphic adenomas are rare tumours of the nasal cavity. They have a higher epithelial and lower stromal component compared to their major salivary gland counterparts and may be misdiagnosed at an early stage leading to more aggressive treatment. Therefore, consideration of this diagnosis if the patient has unilateral nasal mass with obstruction or epistaxis as a presenting complaint can be beneficial. In view of the potential for tumour recurrence, long-term follow-up and careful examination of the nose with an endoscope are necessary. 


\section{ACKNOWLEDGEMENT}

We would like to acknowledge the Doctors and Nursing staff in our department and hospital, who participated in the treatment of this patient.

\section{REFERENCES}

[1] Jassar P, Stafford ND, MacDonald AW. Pleomorphic adenoma of the nasal septum. J Laryngol Otol 1999;113(5):483-5.

[2] Batsakis JG. Tumors of the head and neck. $2^{\text {nd }}$ edn. Baltimore: Williams and Wilkins, 1984:76-99.

[3] Denker A, Kahler O. Handush der Hals. Nasen Ohrenheilkunde 1929;5:202.

[4] Compagno J, Wong RT. Intranasal mixed tumours (pleomorphic adenomas): a clinicopathologic study of 40 cases. Am J Clin Pathol 1977;68(2):213-8.
[5] Tahlan A, Nanda A, Nagarkar N. Pleomorphic adenoma of the nasal septum: a case report. Am J Otolaryngol 2004;25(2):118-20.

[6] Golz A, Ben-Arie Y, Fradis M. Pleomorphic nasoseptal adenoma. J Otolaryngol 1997;26(6):399-401.

[7] Rauchfuss A, Stadtler F. The differential diagnosis of benign neoplasms of the nasal septum. HNO 1981;29(4):124-7.

[8] Freeman SB, Kennedy KS, Parker GS, et al. Metastasizing pleomorphic adenoma of the nasal septum. Arch Otolaryngol Head Neck Surg 1990;116(11):1331-3.

[9] Sabesan T, Ramchandani PL, Hussein K. Metastasising pleomorphic adenoma of the parotid gland. Br J Oral Maxillofac Surg 2007;45(1):65-7. 